\title{
THE METABOLISM OF BLOOD PIGMENTS IN PERNICIOUS ANEMIA
}

\author{
BY K. DOBRINER AND C. P. RHOADS \\ (From the Hospital of the Rockefeller Institute for Medical Research, New York City)
}

(Received for publication September 22, 1937)

Pernicious anemia is believed at present to be caused by a simple deficiency of a substance which is required specifically for the maturation of erythropoietic cells (1). For a considerable period however, up to the discovery of the curative effect of liver, the disease was supposed commonly to be a hemolytic anemia.

Recent developments in the study of the metabolism of the respiratory pigments and of their precursors furnish methods by which the existence of an increased rate of blood formation may be ascertained with greater certainty than has been the case previously. To that end the procedures devised by Dobriner and coworkers $(2,3,4,5,6)$ which use the rate of excretion of coproporphyrin I as an index of the activity of the bone marrow have been employed in three cases of pernicious anemia. Concurrently, quantitative measurements of the rate of excretion of urobilin have been made. In this way an index of the rate of marrow activity has been correlated with an index of the rate of destruction of erythrocytes. For an understanding of the rationale of this procedure a brief review of the metabolism of the porphyrins is required $(7,8,9,10) .{ }^{1}$

Porphyrins are substances which contain a porphin nucleus composed of four pyrrol nuclei united by four methene groups.

The hydrogen atoms numbered 1 to 8 in the formula (Figure 1) are replaced in the naturally

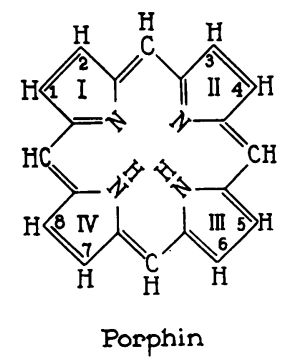

Fig. 1. Structural Formula of Porphin

1 The recently published book by Hans Fischer and Hans Orth, Die Chemie de Pyrrols. Volume II. Pyrrolfarbstoffe. Akademische Verlagsgesellschaft, Leipzig, 1937, should be consulted. occurring porphyrins by a series of substituting groups. For example, the protoporphyrin from which hemoglobin and myoglobin are formed has four methyl, two propionic acid and two vinyl groups substituted in the place of the eight hydrogen atoms in the basic porphin formula.

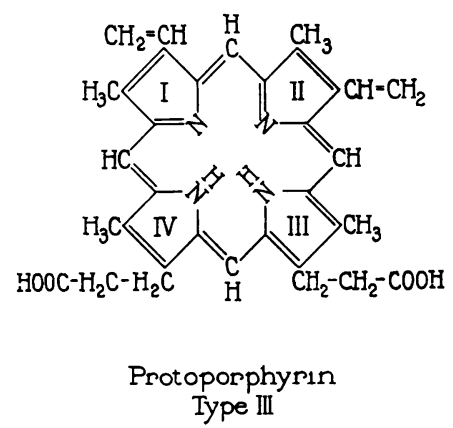

Fig. 2. Structural Formula of Protoporphyrin Type III

From the structural formula of protoporphyrin (Figure 2) it is quite apparent that the different substitution groups can be arranged in different sequences. The compounds thus formed are all termed isomers. It is remarkable that out of the great number of the theoretically possible isomers only a few are selected by nature to take part in biological processes. Although four basic types of these compounds exist and all four have been synthesized by Fischer in the laboratory, only Types I and III derivatives have been shown to occur in nature.

The most important natural porphyrins are Type III protoporphyrin and Type I coproporphyrin. Protoporphyrin, Type III, combines with iron and a protein to form hemoglobin and myoglobin. Cytochrome $\mathrm{C}$ and catalase are also Type III compounds. Coproporphyrin I serves no known purpose in the body and is excreted as a by-product.

According to the recent studies of the subject, coproporphyrin $I$ is excreted at a rate which is constantly proportional to the rate of formation of protoporphyrin Type III compounds (2, 3, 4, $5)$. This suggested the conception that the 2 


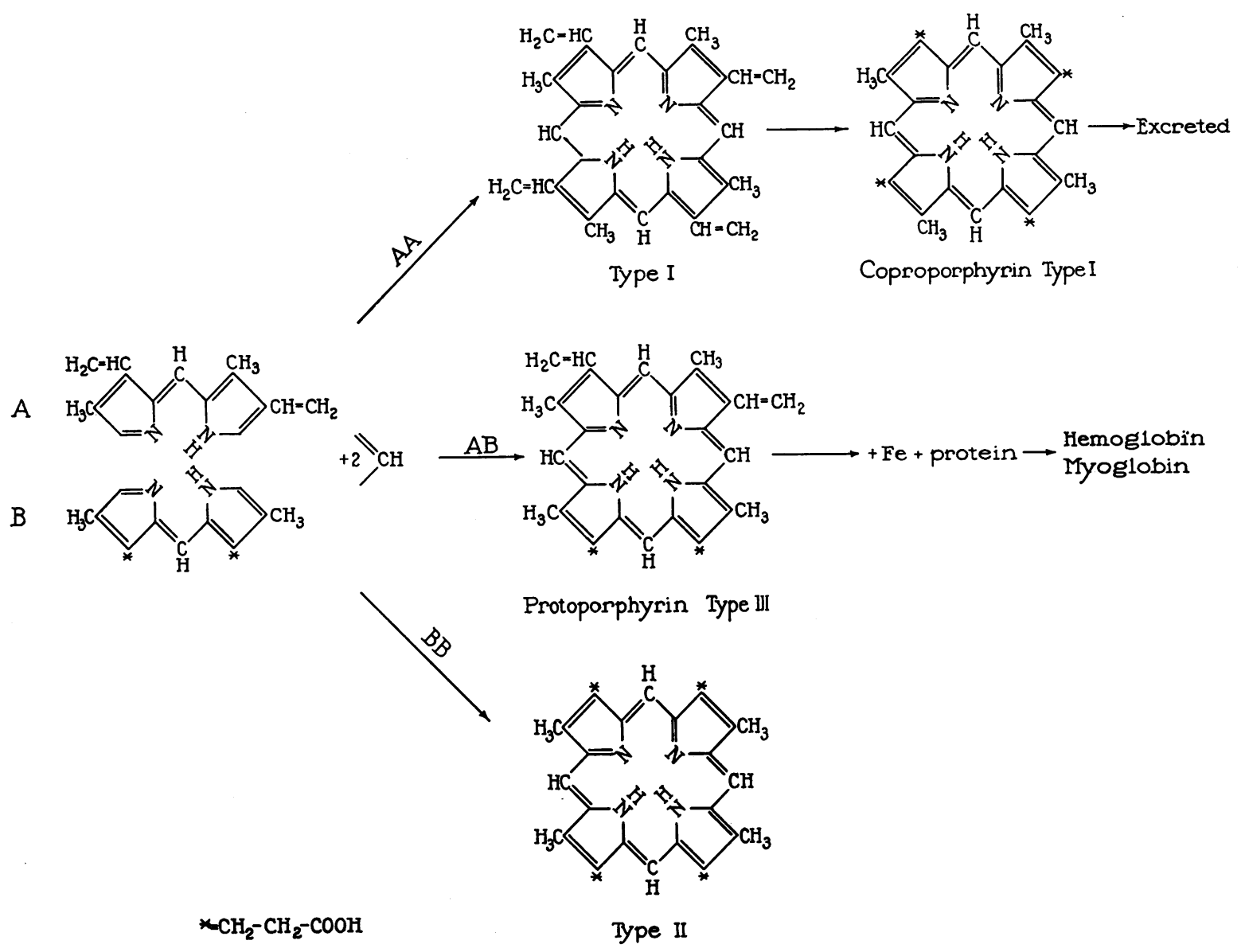

Fig. 3. Scheme of the Concurrent Construction of Hemoglobin and Coproporphyrin Type I

substances are not synthesized independently but are products of the same chemical process. ${ }^{2}$

The exact steps in the natural synthesis of these compounds are of course unknown, but it is assumed that they are formed from relatively simple building stones. The most instructive information concerning possible ways of synthesis is derived from the in vitro studies of Fischer. It must be understood, however, that no evidence proves that exactly the same steps are followed in nature.

Fischer synthesized most of the natural porphyrins from substituted pyrrols. Furthermore, Fisher could combine protoporphyrin III, iron and a protein to form a synthetic hemoglobin. $\mathrm{He}$ suggested the possibility that acetoacetic acid occurring as a product of normal metabolism is one

2 Rimington (30) made a similar suggestion concerning the production of Type III and Type I porphyrins as products of the same synthesis. of the original building stones of this synthesis. This would make understandable a natural synthesis which is similar in general to the one which he developed in the laboratory (10).

A possible explanation of the constantly proportional and concurrent construction of Type III and Type I porphyrins is shown in Figure 3.

If one considers the two pyrromethenes $\mathrm{A}$ and $B$ formed from substituted pyrrols, to be joined together by two methene groups to form porphyrins, there are three possible combinations. (1) Two molecules of A may unite, or (2) two molecules of $\mathrm{B}$, or (3) one molecule each of $\mathrm{A}$ and $B$. As can be seen from the figure the following compounds would form, 1, methyl vinyl porphyrin, 2, methyl vinyl propionyl porphyrin and, 3 , methyl propionyl porphyrin. If the order of substitution be compared with Figure 3, it will be seen that $A B$ is Type III, AA is Type I, and $\mathrm{BB}$ is Type II. 
The individual compounds will be formed in relatively different amounts according to the conditions under which the synthesis operates, and to the relative amounts of $\mathrm{A}$ and $\mathrm{B}$ which take part. Hence, under normal physiological circumstances, the end products may be formed in quantitatively proportional relationships.

The Type II porphyrin which should be formed according to the outline presented has not yet been demonstrated in nature, perhaps due to the great difficulty in obtaining sufficiently large amounts of these compounds to allow separation and identification or it may not be formed at all in the biological synthesis.

The principle that under normal conditions the rate of production of coproporphyrin I is proportional to the formation of protoporphyrin III compounds, and as such is a measure of the rate of formation of respiratory pigment can be strengthened further by experimental evidence. In studies of animals we have induced a rapid regeneration of erythrocytes by causing hemolysis with phenylhydrazine (5). During such experiments we have measured the excretion of coproporphyrin I. As would be predicted from the facts which have been outlined, the excretion of coproporphyrin I was increased proportionally to the rate of formation of the Type III compound (hemoglobin).

Little as is known concerning the natural synthesis of the respiratory pigments, equally little is known of the details of their destruction. Under normal circumstances the bile pigments are de-
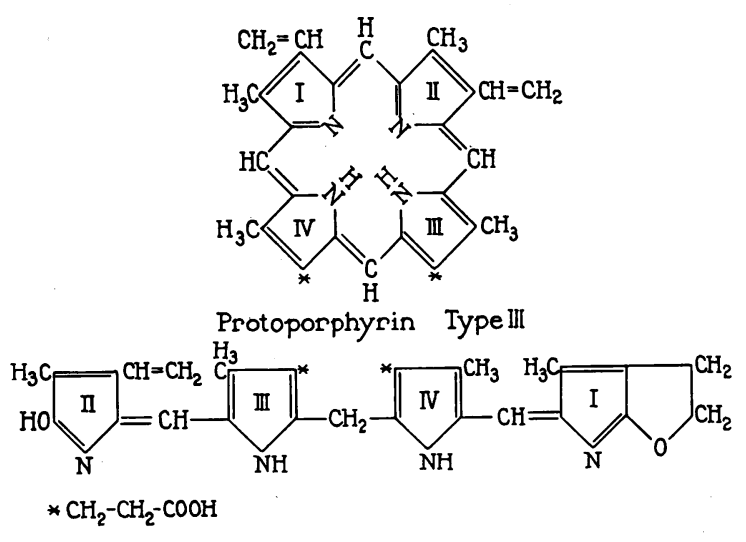

Bilipubin

Fig. 4. Structural Formula of and Relations beTWEeN Protoporphyrin Type III AND BILIRUBin rived from hemoglobin by the opening of the ring of a Type III porphyrin to form bilirubin (Figure 4). The other bile pigments such as urobilin and urobilinogen are derived by reduction and oxidation of bilirubin.

Unfortunately, because of a lack of accurate methods, it is not possible to measure the total bile pigments, and thus to obtain an absolute measure of the rate of destruction of respiratory pigment. Determinations of urobilin are of value, however, as an indication of the relative degree of the processes of blood destruction, provided they are made as comparative studies.

Under pathological conditions the normal processes of formation and of destruction of the respiratory pigments may be disturbed. For example, in certain cases of aplastic anemia (11), in certain types of cirrhosis of the liver (12), and in lead poisoning $(13,14)$ an excretion of Type III coproporphyrin, an abnormal product, takes place.

As may be seen from Figure 5, coproporphyrin I differs from coproporphyrin III in the arrangement of the substituting groups in the porphyrin ring.

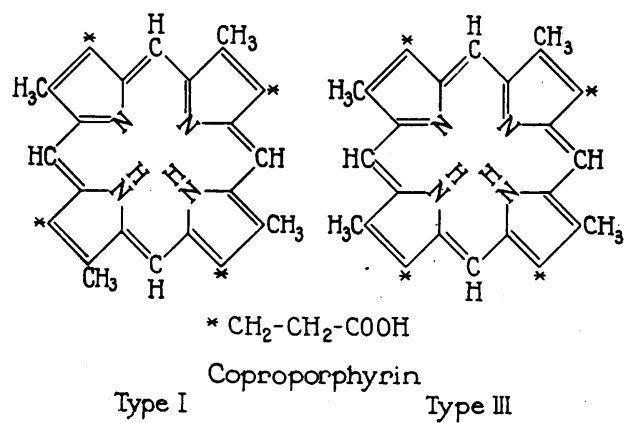

Fig. 5. Structural Formula of Coproporphyrin Type I AND III

Without breakdown to simple pyrrols and resynthesis, it is unlikely that one isomer can be converted into the other, hence unlikely that a porphyrin of one type can be derived from a porphyrin of another type. Two possibilities exist to explain the formation of coproporphyrin Type III. (1) It could be formed by a pathological destruction of protoporphyrin Type III. (2) It could be formed in the course of a pathological synthesis different from that which has been described. 


\section{LITERATURE}

The concept of pernicious anemia as a blood dyscrasia resulting from a lack of maturation of the precursors of erythrocytes was first developed by the histological studies of Peabody (15). He showed that the bone marrow during relapse is hypercellular and that immature, erythroblastic cells predominate. Successive biopsies revealed a decrease in cellularity and a shift to more mature forms with the onset of remission. Liver (16), and the product of the interaction of normal gastric juice and beef muscle (17), were found to be specific in causing remissions to occur; hence they were supposed to contain a specific factor required for normal maturation of erythrocytes.

Certain objections to this interpretation of the histological appearance of the bone marrow have been advanced by Dock (31) from the work of Young and Osgood (18) which indicates that the bone marrow in hemolytic jaundice differs in no way from that of pernicious anemia. Miller and Rhoads (19), in experiments concerning the production of an exceedingly active, cellular bone marrow by bleeding rabbits and returning the hemoglobin, found a degree of immaturity quite analogous to that of pernicious anemia. This observation was confirmed by Steele (20), employing a more exact quantitative technic, and a somewhat different method.

The wide acceptance of the concept of a maturation defect has obscured the accumulated evidence concerning the increased rate of excretion of bile pigment in pernicious anemia during relapse. Whipple (21) in 1928 advanced a hypothesis designed to reconcile the theory of an arrest of maturation with the fact of a heightened output of the products of erythrocytic breakdown. It was assumed that hemoglobin or its precursors are formed extracellularly and are split to bile pigment and excreted as such in the absence of mature erythrocytes to take them up. This requires the demonstration by experiment that hemoglobin or its precursors can be formed in considerable amounts outside of the cell or that it can be converted to bilirubin without passing through the stage of hemoglobin. Fischer has carried out the synthesis of pyrrol to porphyrin and of porphyrin to hemoglobin in the test tube. Furthermore, he has shown that bilirubin must be derived from protoporphyrin Type III by opening the porphyrin ring. No evidence is at hand, however, to indicate that such a process occurs in nature without the participation of hemoglobin preformed in the erythrocytes.

It has been reported previously that an increased excretion of coproporphyrin I in both urine and feces marks the relapse $(22,23,24,25)$ and a lessened excretion in the remission of pernicious anemia $(24,25)$. The reported findings are not conclusive except for the communication of Watson (26) which includes valid data for feces. No experiments are reported in which the rate of excretion of coproporphyrin I and urobilin have been followed together (6).

Could it be demonstrated by experiment that the bone marrow is more active than normal during the time of heightened excretion of bile pigment in relapse and that both processes returned to normal during remission, the case would be strong for the participation of a hemolytic process in the etiology of pernicious anemia.

\section{METHODS}

The methods employed for the separation and quantitative measurement of the excreted porphyrin were those which have been described previously $(2,3,12)$. The urobilin was determined as urobilinogen by the Watson method (27a). The coproporphyrin excreted was identified in each instance by crystallization and determinations of the melting points.

All of the urine and feces passed were collected for three-day periods and were stored in the ice box with toluol as a preservative. Aliquot parts of each sample were analyzed. Single determinations are essentially valueless in studies of this kind, particularly as concerns the excretion in the feces. Control periods of sufficient length to establish the excretion rate as constant were observed.

In the charts the excretion of coproporphyrin $I$ is expressed as micrograms, and of urobilinogen as milligrams. The figures on the ordinates of the charts are multiplied by 10 to obtain the percentage of reticulocytes.

\section{CASE REPORTS}

Case 1, G.C. A 61 years old white male entered the hospital with anemia of four years' duration, during which time inadequate treatment had been employed. Physical examination showed a subicteric tint to the skin, emaciation, and some atrophy of the lingual papillae. Examination of the blood on admission showed erythrocytes 900,000 per cu. mm., leukocytes 3,250 , hemoglobin 23 per cent $\left(100 \mathrm{cc} .=\mathrm{O}_{2}\right.$ combining capacity 19.6 volumes per cent), mean corpuscular volume 1.13, color index 1.21, icteric index 7. The morphology of the erythrocytes was typical of pernicious anemia. For further confirmation, a biopsy of the sternal bone marrow was made and revealed a typical histological picture of pernicious anemia. There was no free hydrochloric acid in the gastric juice after the administration of histamine.

Quantitative determinations of coproporphyrin and urobilin were made during the periods of relapse treatment, and remission (Figure 6). The total coproporphyrin output during the 15 -day control period in relapse averaged 632 micrograms per day and the urobilinogen averaged $442 \mathrm{mgm}$. Shortly after therapy was instituted, the reticulocytes rose rapidly to 60 per cent; during this period there was little change in the total coproporphyrin and urobilinogen output (611 micrograms coproporphyrin and $533 \mathrm{mgm}$. urobilinogen daily average for the 9-day period. The amount of coproporphyrin in the urine decreased from 158 to 100 micrograms. After the reticulocyte response was completed, and 7 days after the onset of therapy, the total amount of coproporphyrin excreted decreased rapidly to a daily average of 261 and 172 micrograms and for the urobilinogen to 40 and 93 


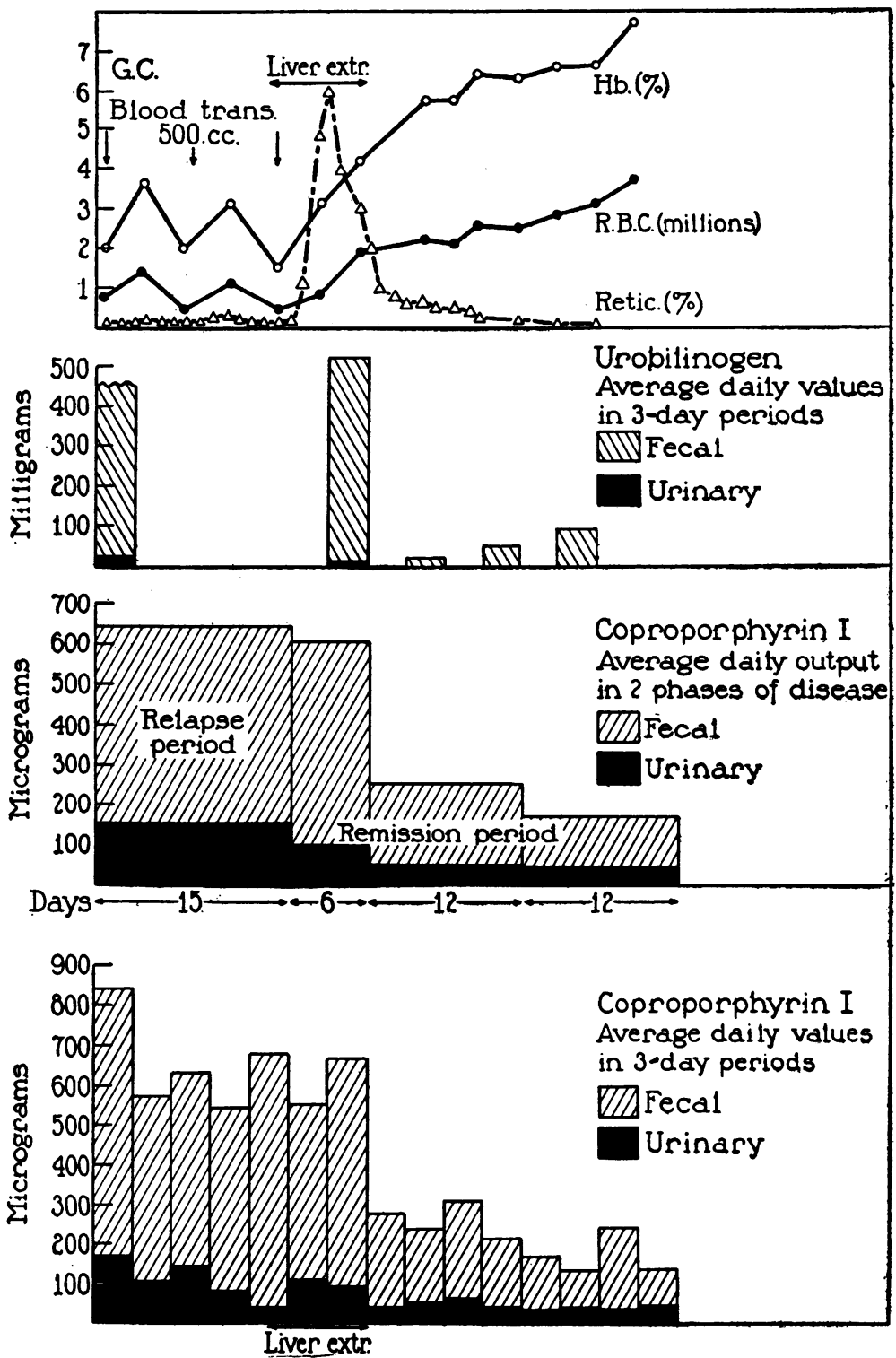

Fig. 6. Coproporphyrin Type I and Urobilinogen Excretion in Case 1

mgm. respectively in the next two 12 -day periods. Increased protoporphyrin was excreted in the feces. The coproporphyrin was identified by determinations of the melting point as coproporphyrin I $\left(242^{\circ} \mathrm{C}\right.$.).

Case 2, C.B. A 23 year old white male clerk was admitted with anemia of three years' duration. Inadequate treatment had been employed. The father had been treated for pernicious anemia. Physical examination showed pallor, atrophy of the lingual papillae, palpable liver and spleen, a subicteric tint to the skin and sclerae. Examination of the blood showed erythrocytes 1,690,000 per cu. mm., hemoglobin 75 per cent (Sahli), leukocytes 4,300 , mean corpuscular volume 134 , color index 1.69 . The morphology of the erythrocytes was typical of per- nicious anemia. There was a total gastric achlorhydria to histamine. Serum bilirubin was $2.0 \mathrm{mgm}$. per cent. The details of treatment and the hematological response are summarized in Figure 7. One injection of $1 \mathrm{cc}$. of concentrated liver extract (Lederle and Co.) was given on the 25th day of observation. On the 34th day, daily therapy with the same preparation was begun. Thus, two periods of treatment and two of relapse were studied.

Quantitative determinations of the rate of excretion of urobilin and coproporphyrin were made over a 25-day control period and two remission periods. The excretion of urobilin during the control or relapse period averaged $900 \mathrm{mgm}$. daily, and the coproporphyrin excretion averaged 610 micrograms daily. The first remission 

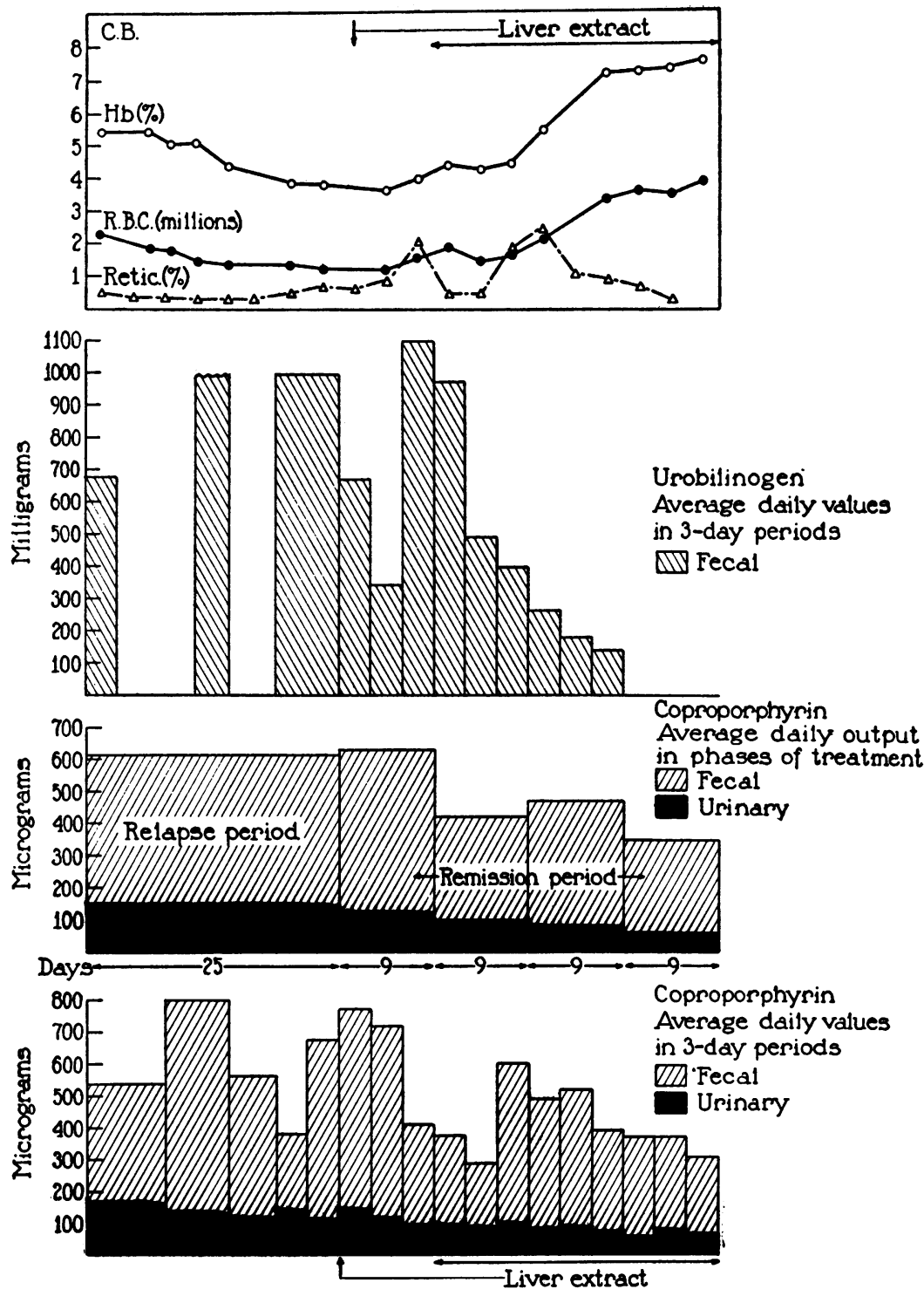

Fig. 7. Coproporphyrin Type I and Urobilinogen Excretion in Case 2

period showed a decrease in the urobilin output to 350 mgm. daily and of coproporphyrin to 288 micrograms daily. The second relapse, a brief one, showed a rise in urobilin output to $1,000 \mathrm{mgm}$. daily and of coproporphyrin to 600 micrograms daily. A second period of treatment resulted in a decrease in the excretion of urobilin to 150 mgm. daily and in the excretion of coproporphyrin to 305 micrograms daily once more. The sensitiveness of the response of the excretion of pigment to the administration of liver extract is admirably shown in this case. The reticulocytes rose to 22 per cent in both remissions. The coproporphyrin excreted was identified as Type I by determinations of the melting point $\left(245^{\circ} \mathrm{C}\right.$. $)$. Protoporphyrin was present in the feces.
Case 3, E.C. A single female seamstress of 55 entered the hospital with anemia of 5 years' duration. She had taken liver extract orally throughout this period. Marked numbness and incoördination of the extremities were present. Physical examination showed a subicteric tint to the skin and sclerae. Vibratory sense was absent in the legs and position sense was impaired. Examination of the blood showed erythrocytes $1,360,000$ per cu. mm., hemoglobin 53 per cent (Sahli), leukocytes 1,950, mean corpuscular volume 149 , color index 1.79. The morphology of the erythrocytes was typical of pernicious anemia (Figure 8).

The daily average excretion of coproporphyrin I during the 9-day control period was 478 micrograms and the 

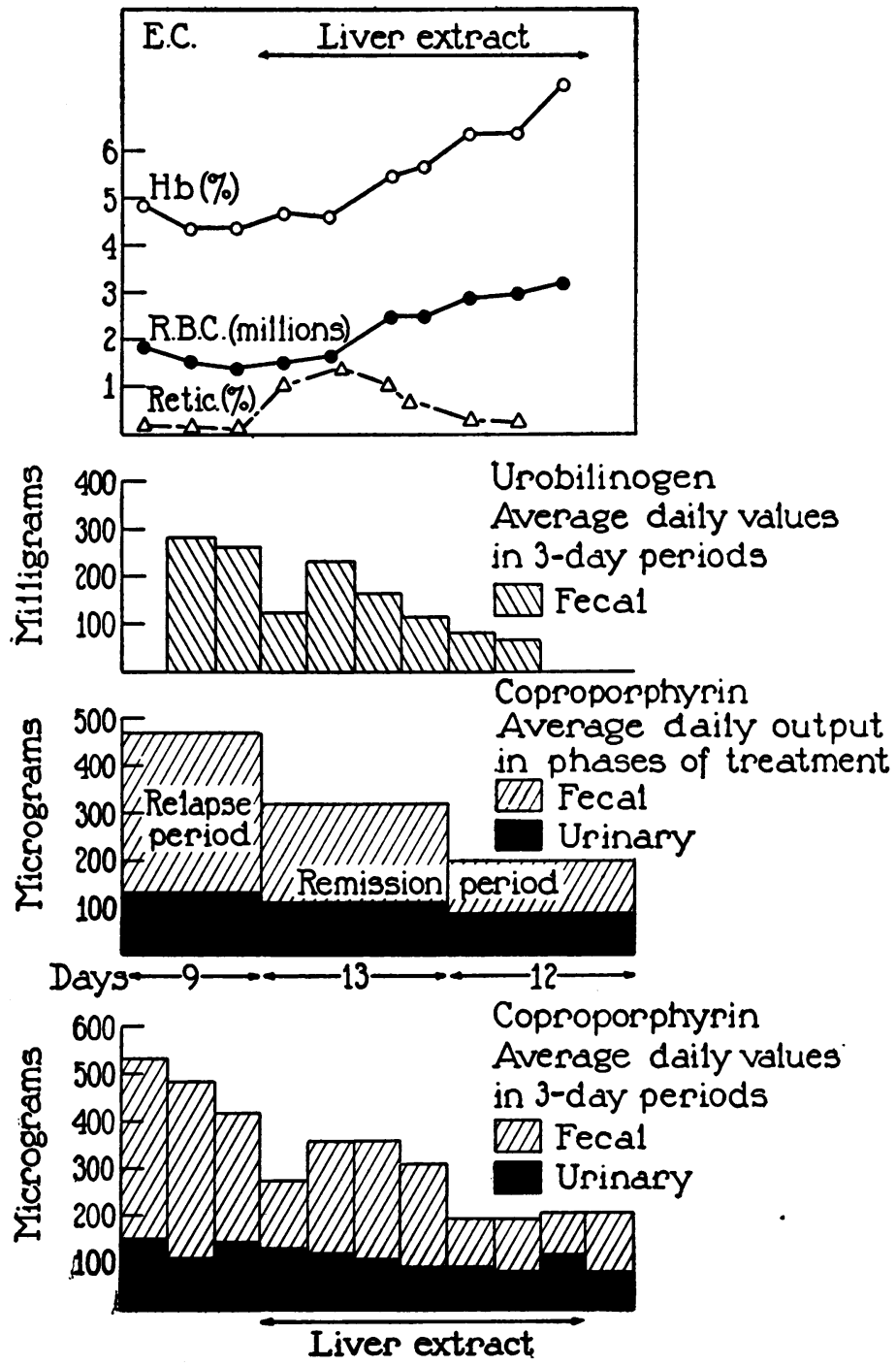

Fig. 8. Coproporphyrin Type I and Urobilinogen Excretion in CASE 3

urobilin during a 6-day period averaged $262 \mathrm{mgm}$. Following daily intramuscular injections of liver extract, the reticulocytes rose to 13 per cent on the seventh day. The rate of excretion of urobilin and of coproporphyrin decreased slowly as the levels of the blood improved. During two consecutive periods of 13 and 12 days respectively the excretion of coproporphyrin I averaged 318 and 200 micrograms daily. The excretion of urobilin averaged 157 and $69 \mathrm{mgm}$. for the same periods. The coproporphyrin I was identified by determinations of the melting point $\left(246^{\circ}\right.$ C. $)$. Protoporphyrin was present in the feces.

\section{DISCUSSION}

A series of observations concerning the metabolism of the porphyrins has been referred to. The theoretical and experimental evidence for employing the rate of excretion of coproporphyrin I as an index of erythropoietic activity has been disdiscussed. The clinical studies reported here indicate that by such an index the bone marrow is abnormally active during the relapse of pernicious anemia and is less active during remission. Concurrent studies of the rate of excretion of urobilin as an index of the rate of destruction of respiratory pigments reveal a similar increase during relapse and a return to low levels during remission. These facts indicate that, during relapse, erythrocytes are being destroyed rapidly and also are 
being formed at a rate more rapid than normal. When remission takes place, the rate of destruction drops quickly to a normal level and the activity of the marrow becomes correspondingly less. In short, the studies suggest that hemolysis is a factor in pernicious anemia. Certain possible objections to this somewhat radical conclusion require discussion.

Experiment has shown repeatedly that destruction of hemoglobin in the body is followed by an increase in the rate of excretion of bile pigment. One objection to the use of this fact as an index of the rate of destruction of erythrocytes is the possibility that bile pigment may be derived from precursors of hemoglobin. Unfortunately, the crucial experiment of injecting free protoporphyrin and then recovering it as bile pigment has not been made, and hence no absolute information is available concerning this point. Watson and Clarke (28) have recently demonstrated, however, that reticulocytes contain more protoporphyrin than do adult erythrocytes. This is strong evidence that the porphyrins are formed intracellularly. If so formed, they probably cannot be converted to bile pigment without the destruction of the cell.

Lastly, the experiment furnished by the anemia resulting from a deficiency of iron is important. There is probably a specific inability to form heme in this condition since Heath, Strauss and Castle (29) have shown that injected iron may be recovered almost quantitatively as hemoglobin, an indication of a lack of iron in the organism. Hence, the defect must lie in the combination of protoporphyrin, iron and globin. There is no reason to suppose that any interference with the formation of porphyrin exists since combination promptly occurs as soon as iron is administered. Were protoporphyrin broken down to bile pigment when not used in forming hemoglobin, there should then be a normal output of bile pigment in the anemia of iron deficiency. In fact, the output of urobilin is sharply reduced below normal, strong evidence that conversion of Type III porphyrin to bilirubin does not occur without the breakdown of hemoglobin.

It has been stated in the past that the methods for measuring bile pigment are not sufficiently accurate to warrant drawing any conclusions from their application. It must be acknowledged that many theoretical objections to the results of the methods exist and that the number of grams of hemoglobin destroyed cannot be calculated from the number of milligrams of bile pigment excreted. The method, however, does allow conclusions as to general changes in the rate of production of bile pigment when subsequent periods are studied.

Reference to the studies of Dobriner, and of Dobriner, Strain and Localio, and to those of Watson in hemolytic states and in pernicious anemia reveals a remarkable similarity between the increased rate of excretion of coproporphyrin I and of urobilin during relapse in these conditions. Furthermore, precisely the same decreased rate of excretion of both pigments is seen after splenectomy in hemolytic jaundice as occurs after the administration of liver extract in pernicious anemia. No one would question the increased activity of erythropoiesis in hemolytic jaundice during relapse, and there seems to be as little reason to question its existence in pernicious anemia.

It should be noted that in both conditions the studies of pigment metabolism indicate that a simple increase of a normal process is present similar to the erythropoiesis induced by hemolysis. It is quite unlike the disorderly and utterly abnormal metabolism of pigment which marks porphyria or aplastic anemia.

The conception of hemolysis in pernicious anemia presented here is in no way incompatible with the etiological mechanism described by Castle. It suggests only that the Castle mechanism should include hemolysis operative only in the presence of a deficiency.

\section{SUMMARY AND CONCLUSION}

1. The rates of excretion of coproporphyrin I and of urobilin in pernicious anemia are elevated during relapse and are restored to normal by specific therapy.

2. Similar changes in the rate of excretion of these two substances are present in induced hemolytic states.

\section{BIBLIOGRAPHY}

1. Castle, W. B., and Minot, G. R., Pathological physiology and clinical description of the anemias. Oxford Loose Leaf Medicine, 1936, 2, 630.

2. Dobriner, K., Porphyrin excretion in the feces in normal and pathological conditions. J. Biol. Chem., 1937, 120, 115.

3. Dobriner, K., Strain, W. H., and Localio, S. A., I. 
Quantitative measurement of coproporphyrin and total coproporphyrin I excretion in normals. Proc. Soc. Exper. Biol. and Med., 1937, 36, 752.

4. Dobriner, K., Strain, W. H., Localio, S. A., Keutmann, H., and Stevens, D. I., II. Coproporphyrin I metabolism and hematopoietic activity. Proc. Soc. Exper. Biol. and Med., 1937, 36, 755.

5. Dobriner, K., Excretion of porphyrin by dogs. Proc. Soc. Exper. Biol. and Med., 1937, 36, 757.

6. Dobriner, K., and Barker, W. H., Total coproporphyrin I excretion in pernicious anemia. Proc. Soc. Exper. Biol. and Med., 1937, 36, 864.

7. Fischer, H., Konstitution der eiweissfreien Farbstoffkomponenten und ihrer Derivate (Chlorophyll). Handb. d. norm. u. path. Physiol., Berlin, 1928, 6, Part I, 164.

8. Fischer, H., Hämin, Bilirubin, und Porphyrine. Die Naturwissenschaften, 1930, 18, 1026.

9. Fischer, H., UUber Hämin und Porphyrine. Verhandl. d. deutsch. Gesellsch. f. inn. Med., 1933, 45, 7.

10. Fischer, H., Utber Porphyrine und ihre Synthesen. Ber. d. deutsch. Chem. Gesellsch., 1927, 2, 2611.

11. Dobriner, K., and Rhoads, C. P., The excretion of porphyrin in refractory and aplastic anemia. (In press. J. Clin Invest., 1938.)

12. Dobriner, K., Urinary porphyrins in disease. J. Biol. Chem., 1936, 113, 1.

13. Grotepass, W., Zur Kenntnis des im Harn auftretenden Porphyrins bei Bleivergiftung. Ztschr. f. physiol. Chem., 1932, 205, 193.

14. Watson, C. J., Concerning the naturally occuring porphyrins. IV. The urinary porphyrins in lead poisoning as contrasted with that excreted normally and in other diseases. J. Clin. Invest., 1936, 15, 327.

15. Peabody, F. W., The pathology of the bone marrow in pernicious anemia. Am. J. Path., 1927, 3, 179.

16. Minot, G. R., and Murphy, W. P., Treatment of pernicious anemia by a special diet. J. A. M. A., 1926, 87, 470.

17. Castle, W. B., Observations on the etiologic relationship of achylia gastrica to pernicious anemia. I. The effect of the administration to patients with pernicious anemia of the contents of the normal human stomach recovered after the ingestion of beef muscle. Am. J. M. Sc., 1929, 178, 748.

18. Young, R. H., and Osgood, E. E., Sternal marrow aspirated during life. Cytology in health and in disease. Arch. Int. Med., 1935, 55, 186.

19. Miller, D. K., and Rhoads, C. P., The effect of hemoglobin injections on erythropoiesis and erythrocyte size in rabbits rendered anemic by bleeding. J. Exper. Med., 1934, 59, 333.
20. Steele, B. F., The effects of blood loss and blood destruction upon the erythroid cells in the bone marrow of rabbits. J. Exper. Med., 1933, 57, 881.

21. Whipple, G. H., Hemoglobin construction within the body as influenced by diet factors; a consideration of anemia problems. Am. J. M. Sc., 1928, 175, 721.

22. Fischer, H., and Zerweck, W., Zur Kenntnis der natürlichen Porphyrine. V. Uber Koproporphyrin im Harn und. Serum unter normalen und pathologischen Bedingungen. Ztschr. f. physiol. Chem., 1924, 132, 12.

23. Duesberg, R., Utber die Anämien. I. Porphyrie und Erythropoese. Arch. f. exper. Path. u. Pharmakol., 1931, 162, 249.

24. Watson, C. J., Concerning the naturally occurring porphyrins. III. The isolation of coproporphyrin' I from the feces of untreated cases of pernicious anemia. J. Clin. Invest., 1935, 14, 116.

25. Brugsch, J. T., Untersuchungen des quantitativen Porphyrinstoffwechsels beim gesunden und kranken Menschen. Ztschr. f. d. ges. exper. Med., 1935, 95, 482.

26. Watson, C. J., Concerning the naturally occurring porphyrins. V. Porphyrins of the feces. J. Clin. Invest., 1937, 16, 383.

27. Watson, C. J., (a) The average daily elimination of urobilinogen in health and in disease, with special reference to pernicious anemia. Standardization of method based on mesobilirubinogen ( $\mathrm{H}$. Fischer). Arch. Int. Med., 1931, 47, 698.

(b) Studies of urobilinogen; II. Urobilinogen in the urine and feces of subjects without evidence of disease of the liver or biliary tract. Arch. Int. Med., 1937, 59, 196.

28. Watson, C. J., and Clark, W. O., The occurrence of protoporphyrin in the reticulocytes. Proc. Soc. Exper. Biol. and Med., 1937, 36, 65.

29. Heath, C. W., Strauss, M. B., and Castle, W. B., Quantitative aspects of iron deficiency in hypochromic anemia. (The parenteral administration of iron.) J. Clin. Invest., 1932, 11, 1293.

30. Rimington, C., Some cases of congenital porphyria in cattle: Chemical studies upon the living animals and post mortem material. The Onderstepoort Journal of Veternary Science and Animal Industry, 1936, 7, 597.

31. Dock, W., The importance of hemolysis in the pathogenesis of macrocytic anemia. Medical papers dedicated to Dr. Henry A. Christian, Stanford University School of Medicine, February, 1936, 545. 